Trinity University

Digital Commons @ Trinity

Psychology Faculty Research

Psychology Department

$12-2014$

\title{
Reducing Eating Disorder Risk Factors: A Controlled Investigation of a Blended Task-Shifting/Train-the-Trainer Approach to Dissemination and Implementation
}

\author{
Lisa S. Kilpela \\ Trinity University, Ismith9@trinity.edu \\ Kaitlin Hill \\ Trinity University, khill1@trinity.edu \\ Mackenzie Kelly \\ Trinity University, mkelly4@trinity.edu \\ Joanna Elmquist \\ Trinity University, jelmquis@trinity.edu \\ Paige Ottoson \\ Trinity University, pottoson@trinity.edu \\ Follow this and additional works at: https://digitalcommons.trinity.edu/psych_faculty \\ depart dqage for additional authors \\ Publication Details \\ Behaviour Research and Therapy
}

\section{Repository Citation}

Kilpela, L.S., Hill, K., Kelly, M.C., Elmquist, J., Ottoson, P., Keith, D., Hildebrandt, T., \& Becker, C.B. (2014).

Reducing eating disorder risk factors: A controlled investigation of a blended task-shifting/train-the-trainer approach to dissemination and implementation. Behaviour Research and Therapy, 63, 70-82. doi: 10.1016/j.brat.2014.09.005

This Article is brought to you for free and open access by the Psychology Department at Digital Commons @ Trinity. It has been accepted for inclusion in Psychology Faculty Research by an authorized administrator of Digital Commons@ Trinity. For more information, please contact jcostanz@trinity.edu. 


\section{Authors}

Lisa S. Kilpela, Kaitlin Hill, Mackenzie Kelly, Joanna Elmquist, Paige Ottoson, D. Keith, Thomas Hildebrandt, and Carolyn Becker 


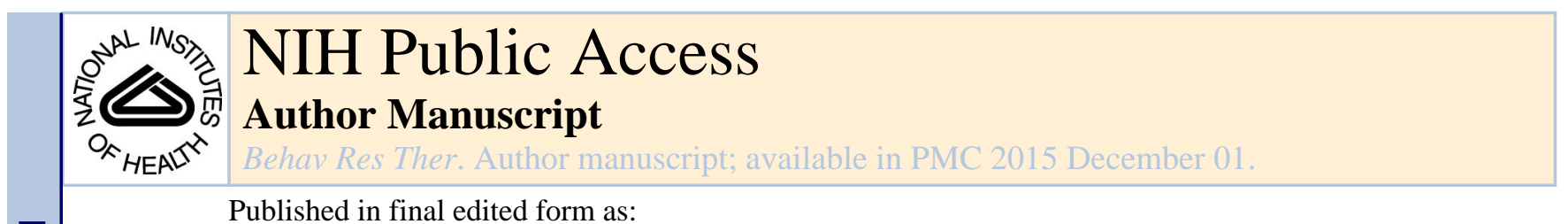

Published in final edited form as:

Behav Res Ther. 2014 December ; 0: 70-82. doi:10.1016/j.brat.2014.09.005.

\title{
Reducing eating disorder risk factors: A controlled investigation of a blended task-shifting/train-the-trainer approach to dissemination and implementation
}

\author{
Lisa Smith Kilpela, Ph.D. ${ }^{a}$, Kaitlin Hill, B.A. ${ }^{a, 1}$, Mackenzie C. Kelly, M.A. ${ }^{a}{ }^{1}$, Joanna \\ Elmquist, B.A. ${ }^{\mathrm{a}, 1}$, Paige Ottoson, B.S. ${ }^{\mathrm{a}, 1}$, Demetra Keith, B.A. ${ }^{\mathrm{a}, 1}$, Thomas Hildebrandt, \\ Psy.D. ${ }^{b}$, and Carolyn Black Becker, Ph.D. ${ }^{a}$ \\ aDepartment of Psychology, Trinity University, San Antonio, TX, USA \\ ${ }^{b}$ Department of Psychiatry, Mount Sinai School of Medicine, New York, NY, USA
}

\section{Abstract}

\begin{abstract}
Recent advances in psychological intervention research have led to an increase in evidence-based interventions (EBIs), yet there remains a lag in dissemination and implementation of EBIs. Taskshifting and the train-the-trainer (TTT) model offer two potential strategies for enhancing reach of EBIs. The Body Project, an EBI found to prevent onset of eating disorders, served as the vehicle for this dissemination/implementation study. The primary aim of this study was to determine if training of peer-leaders for the Body Project could be task-shifted to undergraduate students using a hybrid task-shifting/TTT model. Our secondary aim was to determine if subgroups of participants evidenced different trajectories of change through 14-month follow-up. Regarding the first aim, we found almost no evidence to suggest that a presence of a doctoral-level trainer yielded superior participant outcomes compared to training by undergraduates alone. Regarding Aim 2, almost all classes for all variables evidenced improvement or a benign response. Additionally, for three key risk factors (thin-ideal internalization, body dissatisfaction, and ED
\end{abstract}

(C) 2014 Elsevier Ltd. All rights reserved.

Corresponding Author: Lisa Smith Kilpela, Ph.D., Department of Psychology, Trinity University, San Antonio, TX, USA. Tel: 1-210-999-8381, 1smith9@trinity.edu. Thomas Hildebrandt, Psy.D., Department of Psychiatry, Mount Sinai School of Medicine, New York, NY, USA. tom.hildebrandt@mssm.edu. Carolyn Black Becker, Ph.D., Department of Psychology, Trinity University, San Antonio, TX, USA. cbecker@trinity.edu.

${ }^{1}$ The following authors have relocated since the work completed. Present addresses are:

Kaitlin Hill, B.A., Department of Psychology, University of Hawai'i at M3noa, 2530 Dole Street, Sakamaki Hall C400, Honolulu, HI, USA. khill3@ @awaii.edu

Mackenzie Kelly, M.A., Department of Psychology, University of Hawai'i at M3noa, 2530 Dole Street, Sakamaki Hall C400,

Honolulu, HI, USA. mkelly4@ hawaii.edu

Joanna Elmquist, B.A., Department of Psychology, University of Tennessee, 1404 Circle Dr., Austin Peay Building 204, Knoxville, TN, USA. jelmquis@ vols.utk.edu

Paige Ottoson, B.S., Department of Psychology, Palo Alto University, 1791 Arastradero Rd, Palo Alto, CA, USA. paige.e.ottoson@gmail.com

Demetra Keith, B.A., Assumption College, 500 Salisbury Street, Worcester, MA, USA. demetra.keith@assumption.edu

Conflict of Interest Statement

Dr. Becker is Co-Director of the Body Project Collaborative, which was created in 2012 to support dissemination and implementation of the Body Project. Dr. Kilpela serves as a trainer for the Body Project Collaborative.

Publisher's Disclaimer: This is a PDF file of an unedited manuscript that has been accepted for publication. As a service to our customers we are providing this early version of the manuscript. The manuscript will undergo copyediting, typesetting, and review of the resulting proof before it is published in its final citable form. Please note that during the production process errors may be discovered which could affect the content, and all legal disclaimers that apply to the journal pertain. 
symptoms) virtually all trajectories showed improvement. This study provides initial support for the use of a blended task-shifting/TTT approach to dissemination and implementation within prevention generally, and further support for broad dissemination of the Body Project specifically.

\section{Keywords}

Train-the-Trainer; Task-shifting; Dissemination; Implementation; Eating Disorders; Prevention

Researchers have made notable advances in the development and testing of psychological interventions, resulting in a significant increase in evidence-based interventions (EBIs). Yet, one common critique of EBIs concerns the gap between the scientific evidence supporting such interventions and clinical application and/or utility in community practice settings (e.g., Kazdin \& Blase, 2011; Lilienfeld et al., 2013; Proctor et al., 2009; McHugh \& Barlow, 2010). In other words, there remains a significant lag in the process of dissemination and implementation following the production and scientific testing of EBIs. This reduces the day-to-day clinical impact of these interventions, despite the fact that providers are increasingly being asked by various constituents to provide EBIs (Proctor, 2004; Proctor et al., 2009).

Kazdin and Blase (2011) and others (e.g., Fairburn \& Patel, 2014) have further noted that even if every clinician offered the best available EBI to every client, the field still would be limited in reducing the global burden of mental illness because one-on-one therapy has limited scalability (i.e., limited capacity to be scaled up to reach large populations without losing effectiveness). Simply put, there will never be enough expert therapists to provide services to everyone who could use them, and the one-on-one expert-provider therapy model is too expensive, particularly in resource poor environments (Fairburn \& Patel, 2014; Kazdin \& Blase, 2011). A number of solutions have been proposed to address the problems outlined above. Among these include an increased focus on prevention, task-shifting to less expensive providers, and use of a train-the-trainer model (Fairburn \& Patel, 2014; Fairburn \& Wilson, 2013; Kazdin \& Blase, 2011; Zandberg \& Wilson, 2012).

Although prevention historically has received somewhat less attention from mental health specialists, prevention has been used widely in the public health field to reduce suffering in other areas of healthcare. For instance, public health interventions, which commonly target prevention of health problems, increased the average life expectancy in the United States by 25 years during the $20^{\text {th }}$ century (Centers for Disease Control and Prevention (CDC), 1999). Prevention targets included, but were not limited to, variable risk factors for such health concerns as infectious diseases, foodborne illness, tooth decay, birth defects, lung cancer and emphysema (CDC, 1999). Variable risk factors (e.g., smoking behavior) are risk factors that increase risk for a given disorder and can be manipulated to reduce risk (Jacobi, Hayward, de Zwann, Kraemer, \& Agras, 2004). Variable risk factors, thus, provide targets for prevention efforts. In contrast, fixed risk factors (e.g., gender) help identify risk but do not offer viable prevention targets. As noted by Kazdin and Blase (2011), a reduction in the global burden of mental illness will, at some level, require prevention to reduce the onset of mental illness, which in turn will reduce incidence, and the necessity and cost of treatment. 
Task-shifting, which involves delivering EBIs via less expert (and expensive) providers, offers another option for expanding the impact of efforts to reduce mental health suffering (Patel, Chowdhary, Rahman, \& Verdeli, 2011). This often consists of shifting from professionals to lay persons as providers, but also can include shifting work from a more expert/expensive professional to a less expert/expensive professional. Therefore, taskshifting both has the potential to markedly reduce the cost of intervention delivery as well as significantly increase the availability of providers. When combined with community participatory research methods (see Israel, Eng, Schulz, \& Parker, 2005 for discussion of community participatory research), task-shifting also can increase access to difficult to reach populations by engaging gate-keepers (e.g., community leaders) both as providers and as research collaborators.

Yet another option for improving the impact of EBIs involves a train-the-trainer (TTT) approach (Herschell, Kolko, Baumann, Davis, 2010; Zandberg \& Wilson, 2012). The TTT model typically involves training providers to deliver training in a given EBI to other providers. To some degree this involves task-shifting, usually from a very expert/expensive trainer (e.g., the person who creates a form of CBT for eating disorders) to a moderately expert/expensive provider (e.g., licensed CBT therapist at a mental health clinic). It does not, however, typically involve task-shifting on the scale that might be employed in other settings (e.g., from a professional to a lay person). Although the TTT approach has been found successful for both traditional psychotherapy and guided self-help in a few studies (e.g., Wade, Treat, \& Stuart, 1998; Zandberg \& Wilson, 2012), it also has been critiqued as insufficiently scalable. For instance, Fairburn and Wilson (2013) note that the TTT approach would take far too long as the primary method of training therapists to implement EBIs aimed at treatment. The typical task-shift from very expensive/expert trainers to moderately expensive/expert providers in the psychotherapy TTT model also limits this approach in terms of financial and human resource costs. It is unclear, however, if the same limitations apply to prevention, where there also is preliminary support for a TTT model (Perez, Becker, \& Ramirez, 2010). It is important to note that the discussed solutions should not be viewed as mutually exclusive. In fact, as can be seen from the dissemination case study below, layering solutions often will have a greater impact.

\section{The Body Project: A Case Example in Dissemination and Implementation}

The Body Project is a 4-hour body image intervention that has been found to prevent the onset of eating disorders (Stice, Rohde, \& Shaw, 2013; Stice, Marti, Spoor, Presnell, \& Shaw, 2008a). Based on the dual pathway model of bulimia nervosa (Stice, Ziemba, Margolis, \& Flick, 1996), the Body Project targets internalization of the thin-ideal standard of female beauty using a cognitive dissonance-based approach (Stice, Rohde, \& Shaw, 2013). Cognitive dissonance is an uncomfortable psychological state that results when an individual's actions conflict with his/her beliefs (Festinger, 1957). In the case of the Body Project, participants are encouraged to voluntarily engage in anti-thin-ideal behavior via speech and action, which conflicts with pro-thin-ideal beliefs resulting in cognitive dissonance and a subsequent reduction in thin-ideal internalization. This reduction in thinideal internalization then theoretically cascades into a reduction of numerous variable risk factors for eating disorders including body dissatisfaction, dietary restraint, negative affect 
and ultimately early stage eating disorders pathology (Jacobi \& Fittig, 2010; Stice, Rohde, \& Shaw 2013). The Body Project has been branded under a variety of names for different dissemination efforts (e.g., Reflections: Body Image Program; Succeed Body Image Programme); because current dissemination efforts largely have coalesced under the Body Project brand, for this paper we use this title.

The Body Project is supported by substantial efficacy and effectiveness research generated by multiple labs (Becker, Smith, \& Ciao, 2005; Becker, Smith, \& Ciao, 2006; Becker, Bull, Schaumberg, Cauble, \& Franco, 2008a; Becker, Bull, Smith, \& Ciao, 2008b; Becker et al., 2010; Matusek, Wendt, \& Wiseman, 2004; Roehrig, Thompson, Brannick, \& van den Berg, 2006; Stice, Mazotti, Weibel, \& Agras, 2000; Stice, Chase, Stormer, \& Appel, 2001; Stice, Trost, \& Chase, 2003; Stice, Shaw, Burton, \& Wade, 2006; Stice \& Presnell, 2007; Stice et al., 2008a; Stice, Shaw, Becker, \& Rohde, 2008b; Stice, Rohde, Gau, \& Shaw, 2009; Stice, Rohde, Shaw, \& Gau, 2011; Stice, Rohde, Durant, Shaw, \& Wade, 2013). Indeed no other body image intervention and eating disorder prevention program is supported by more research than the Body Project (see Becker, MacKenzie, \& Stewart, in press for review). The Body Project has been found to yield long-term effects (i.e., 1-3 years) in controlled trials, and efficacy and effectiveness research support its use in both high school and university samples (Becker et al., in press). Research also supports the theoretical underpinnings of the Body Project (see Stice, Becker, \& Yokum, 2013 for review).

Additionally, research investigating the Body Project has tested some of the approaches mentioned above to improve dissemination and implementation of this program. For instance, community participatory research (see Becker, Stice, Shaw, \& Woda, 2009 for additional details) by our lab has demonstrated that delivery of the Body Project can be taskshifted from professional or graduate-level providers to undergraduate peer-leaders (Becker et al., 2006; 2008a; 2010; Perez et al., 2010). Relevant to dissemination, we began studying task-shifting because we lacked the financial and staffing resources to implement the Body Project exclusively with higher level/more expensive providers. Also, we have found that many universities prefer the peer-leader approach both for cost reasons and because it provides leadership experience for students.

In 2008, we launched a North American-based Body Project dissemination effort in partnership with the Tri Delta sorority. The aim of the project was to disseminate the peerled version of the Body Project to Tri Delta university chapters throughout North America as well as to other universities and/or sororities that might wish to implement it. This dissemination project was designed from the start to capitalize on both the task-shifting and community participatory methods that had already been tested. Yet, it rapidly became clear that task-shifting alone would not be sufficient to meet our dissemination goals secondary to financial, time, and staffing constraints. Thus, we turned to the TTT model as an additive component.

The rationale for adding the TTT model can be demonstrated mathematically. In the case of the Body Project, if one very expensive provider (VEP; e.g., licensed psychologist) runs ten 4-hour groups in Year-1 with 10 participants in each group, 40 VEP hours yields 100 participants completing the program or 2.5 complete program participants/VEP hour 
invested. This is superior to one-on-one psychotherapy, but still is not terribly efficient. Moving to a task-shifting approach in Year-2, the VEP spends 30 hours training 36 peerleaders. Peer-leaders run groups in teams of 3 , yielding 12 groups. Thus, if each peer-leader runs a single group then 30 VEP hours translates to 120 participants completing the program, or 4 complete program participants/VEP hour. If peer-leaders agreed to run two groups each then 240 participants complete the program, yielding 8 complete program participants/VEP hour.

Although this latter scenario offers substantial improvement on 2.5 participants/VEP hour, it remains insufficient for large scale dissemination. If, however, in Year-3, the VEP takes 4 peer-leaders from Year-2 and trains them as trainers during the 30 hours of peer-leader training for the next cohort of peer-leaders, then 30 hours of VEP time in Year-3 not only translates to 36 peer-leaders and 240 participants, but also 4 trainers. Collectively, these trainers can substantially increase both the number of peer-leaders and participants in Year-3 that result from the investment of 30 VEP hours. It is important to note that in this model task-shifting occurs on two levels, both at the group leader level and at the trainer level. Of course, the VEP also could task-shift training to a less expensive professional.

The above rationale provided the foundation for the creation of Body Image Academy (BIA). BIA served as the centralized training program for this Body Project dissemination effort over a 4-year period, during which time the Body Project was disseminated to over 100 universities throughout North America. Based on significant pilot testing (e.g., Becker et al., 2006; 2008a; Perez et al., 2010), BIA was designed as a two-day intensive training experience that consisted of two simultaneous training tracks. The first training track, which is the focus of the present study, consisted of Tri Delta undergraduate students. Each sorority chapter that participated in BIA in a given year sent two students to be trained. Of note, during the course of BIA we task-shifted the training-of-trainers from one VEP $(\mathrm{PhD}$ level) to one VEP plus three moderately expensive providers (MEP; masters level) who yielded good reliability with the VEP1. Thus the "master" trainers for BIA consisted of one VEP and 3 MEPs. Tri Delta students at BIA were trained to run the Body Project and trained-to-train co-peer-leaders back at their home universities. Co-peer-leaders could assist a BIA trained peer-leader in running the Body Project but were not allowed to run the Body Project independently in the absence of a BIA trained peer-leader. Thus, pairs of students were deployed back to their home institutions from BIA to train co-peer-leaders, and implement the Body Project in their chapters, which ranged in size from approximately 30300 females. Typically, approximately 25 chapters participated per year.

Although BIA was based on significant pilot testing and clinical experience working with undergraduate students as providers of the Body Project, at the time BIA was launched

\footnotetext{
${ }_{1}$ Reliability between MEPs and VEP was established via a "round robin” approach during Body Image Academy (BIA). Tri Delta's BIA included hosting simultaneous training groups in different rooms at one location. Trainers then rotated through the individual training groups during every BIA. For instance, during an early BIA which involved three simultaneous training groups, each trainer started in one group and then at each break rotated to a different training group. This meant that the VEP trained 1/3 of each training group. Further, because of the repetitive nature of the actual training any inconsistencies in training content or supervision was quickly questioned by participants. This facilitated ongoing checking between trainers to establish that training was consistent, the development of a standard training checklist to make sure that all important points were covered, and also led to the dismissal of a fourth MEP trainer who showed poor reliability with the rest of the trainers.
} 
undergraduate students had only served as co-trainers of peer-leaders in the presence of a VEP or MEP. Thus, we had no controlled data that clearly demonstrated whether undergraduate students would be able to train co-peer-leaders without a professional in the training room. The present study was designed as a conservative controlled test of the student training track of BIA.

\section{The Current Study}

The primary aim of this study was to determine if undergraduate students could be trainedto-train peer-leaders for the Body Project. In this study, 3 consecutive yearly cohorts of peer-leaders were randomly assigned to receive standard training by a VEP plus undergraduate trainers (VEP+UT) as in earlier trials (Becker et al., 2006; 2008a; 2010) or experimental training by undergraduate trainers alone (UTA). The primary outcomes included changes in variable eating disorder risk factors in participants who received the Body Project delivered either by peer-leaders trained by VEP+UT or by peer-leaders trained by UTA (Figure 1). We describe this as a conservative test of BIA in that BIA students were trained to run the program and train co-peer-leaders (i.e., peer-leaders that assisted the BIA trained peer-leaders). In contrast, in the present study, students were trained-to-train peerleaders who ran the program without the presence of any peer-leaders trained by a VEP. In terms of hypotheses, although we expected participants in both groups to show improvement, we hypothesized that the VEP+UT group would show greater reductions in dependent variables as compared to UTA.

The secondary aim of the present study was to determine if different subgroups of participants evidenced different trajectories of change across the 14-months of the study. Researchers are increasingly recognizing that marked heterogeneity in response may exist within a sample receiving a given intervention (e.g., Gueorguieva, Mallinckrodt, \& Krystal, 2011), and that traditional statistical analyses may mask important subgroup differences. In the case of the present study, viewing the sample as a single group also might mask important trainer differences. For instance, type of trainer might not matter for participants with lower baseline pathology, but might matter for those with higher levels of pathology. To our knowledge, this has never been explored in a trial aimed at reducing eating disorder risk factors, which limited our ability to predict trajectories. Thus, we had no specific hypotheses.

\section{Method}

Participants

New members entering the local sororities at a small liberal arts university over three consecutive years (2009-2011) participated in this study. A total of 354 females accepted invitations to join one of the seven campus sororities during the three years of the study. Of these, 297 were randomized into program groups (see Procedure). Reasons for nonrandomization included deciding to drop out of the sorority altogether or having an excused absence (e.g., class or sport conflict). Of the 297 randomized, 285 sorority members (96\%) agreed to participate in the voluntary study associated with this program, which consisted of completing a series of questionnaires (i.e., participants could go through the Body Project 
program but not complete questionnaires). Participants ranged from 18 and 21 year of age, with a mean age of $18.71(S D=0.74)$. Participants' mean Body Mass Index (BMI), calculated from self-reported weight and height, was $22.16(S D=3.22)$ and fell in the normal adult weight range. Seventy-six percent (76.6\%) of the sample was Caucasian, 12.7\% was Hispanic, 3.9\% was Asian, $1.8 \%$ was African American, $6.7 \%$ endorsed multiple races, and $5.7 \%$ of the sample did not respond to this question.

\section{Procedure}

Overview and participant flow-The intervention sessions of the Body Project were semi-mandatory for all sorority new members during orientation (i.e., all new members attended the program unless granted an excused absence by their sorority); however, participation in the study (i.e., completion of self-report assessments) was completely voluntary. Both the study and the program received approval from all sorority presidents, campus Greek council, the student affairs office, and the Institutional Review Board.

Just prior to starting the Body Project, all new members gathered en masse for a meeting in which we described the history of the Body Project on campus. At this meeting, they also learned the difference between the semi-mandatory program and the optional study. Members then signed consent and completed the questionnaire packet before breaking into their preassigned smaller groups for participation in the first Body Project session; each group consisted of a mix of women from all sororities. The second session was held one week later.

To ensure relatively equal representation of each sorority in each of the intervention groups we utilized stratified randomization by sorority to assign participants to one of 12 groups. Intervention groups were then randomly assigned to condition. We ran all groups simultaneously in February of each year of the study. Each group was led by unpaid peerleaders (PLs). Participants remained blinded to intervention condition, which contained identical content, as described below.

Of the 285 participants, 144 were randomized to the VEP+UT group, and 141 to the UTA group. In terms of retention, $80.6 \%$ in VEP+UT and $80.2 \%$ in UTA completed postintervention assessments, $79.9 \%$ in VEP+UT and $83.7 \%$ in UTA completed 8-week followup, 70.9\% in VEP+UT and 79.5\% in UTA completed 8-month follow-up, and 67.4\% in VEP +UT and 59.6\% in UTA completed 14-month follow-up. Participants were not paid or compensated in any way for their participation in the study. We should note that the drop in participation at 14 months was at least partially due to a factor completely unrelated to the study. During the final year of 14-month follow-up data collection, two sororities were placed into suspended status by the university administration. It was clear that this markedly decreased their members' willingness to complete questionnaires.

Intervention: The Body Project-The Body Project intervention consisted of two, 2hour group sessions administered by 2-3 PLs, and both conditions contained identical program content. The first session began by seeking voluntary commitment to participate in the session from members. The session then included a) collectively defining the societal thin-ideal and contrasting it with the healthy ideal; b) reviewing the origin of this societal 
ideal; c) brainstorming and collectively discussing the costs involved with pursuit of the thin-ideal; d) completing a verbal challenge exercise in which members first identified past pressures to pursue the thin-ideal, and then brainstormed and shared statements to challenge those pressures now; and e) receiving a home exercise in which members stood in front of a mirror in the privacy of their own rooms while wearing revealing clothing, and recording positive physical, emotional, and social qualities. The second session involved a) reviewing the mirror exercise and sharing qualities they appreciated about themselves; b) completing role plays in which the PLs acted as a friend pursuing the thin-ideal and the members were charged with talking the PL out of her pursuit; c) engaging in a mini role-play exercise during which participants challenged pro-thin-ideal "fat talk" statements; d) developing a list of activism activities for the sororities to complete that counter pressures to conform to the thin-ideal; e) receiving an exit exercise in which members select her own self-affirmation exercise to practice after the program that reaffirms challenging the thin-ideal (e.g., make a pact with a friend to stop negative body talk); and f) wrapping up the program by each member sharing a final comment about her experience in the program (Becker \& Stice, 2008).

Peer-leader training-We recruited PLs via informational sessions with sorority members who had previously participated in the Body Project as new members. We asked PL volunteers to self-screen for significant body image concerns or disordered eating behaviors, as PLs serve as role models for the program. No screening instrument was used. We explain to PLs that if they have significant body image concerns or an active eating disorder they will undermine the actual program with an appearance of hypocrisy. They also are told that they are welcome to be a PL in the future once they are in recovery or have reduced their body image concerns to normative levels. We have used this strategy for over a decade with this community with no evidence of significant problems.

Interested PLs were then largely randomized to be trained either directly by the VEP master trainer (licensed clinical psychologist) with undergraduate co-trainers (VEP+UT) or by trained undergraduate trainers alone (UTA). We were unable to use pure randomization to assign PLs to training condition because in some cases scheduling limitations (i.e., a PL could only train at very limited times) dictated which type of training the PL received. PLs were unaware that there were two pre-planned training conditions and were not compensated for their time. We have a history of over 10 years with both this community and its leaders using community participatory research methods; being a PL is viewed as an important leadership and service opportunity.

Training sessions for PLs in both conditions were structured identically. PLs completed two, 4.5-hour experiential training sessions, one training session for each program session. We divided PLs into teams of 3-4 PLs, with an effort to mix sorority affiliation in each team. Each team was then assigned to a training group including 3-4 teams, totaling 12-16 PLs. We trained 35 PLs in the first year, 42 PLs in the second year, and 42 PLs in the final year of this study. At training group sessions, PLs first received the intervention manual, and then PL teams rotated taking turns leading an abbreviated version of each session of the Body Project, while the other teams acted as participants in order to simulate an intervention session. Therefore, each PL team led each Body Project session once and served as 
participants 2-3 times within their training group. After each abbreviated Body Project session, PLs received 20-30 minutes of feedback from their trainers targeting increased adherence and leadership skills with groups.

Lastly, audiotapes of $60 \%$ of sessions of the Body Project were reviewed to assess PL adherence to the intervention protocol and evaluate potential adherence differences across training conditions. PLs were rated on Likert scales assessing the degree to which they completed all core steps in the intervention. Although degree of implementation was rated (i.e., adherence) we did not assess the skill level displayed by PLs (i.e., competence). Thus, a given PL might ask all requisite questions and wait for responses in a given section, therefore attaining a high adherence rating, despite doing so in a manner that would be viewed as less competent (e.g., allowing less than optimal time for the largest array of responses given time management demands). Masters-level trainers from BIA and trained undergraduate RAs who were blind to PL training condition rated session tapes for adherence.

Blended task-shifting/train-the-trainer (TTT) training-Undergraduate trainers in the current study consisted of research assistants (RAs) who previously served as PLs in earlier studies (or earlier in the present study). As with students who attended BIA, RA's were trained experientially to train other undergraduate PLs; training occurred in four phases over the three academic years that we recruited new participants into the study. Phase one, which took place during the spring prior to the start of the study, consisted of one RA completing 38 hours of training by co-running all Body Project trainings for a previous study with the VEP. During this time the VEP modeled delivery of PL supervision and the RA gradually took over increasing responsibility for the trainings, receiving ongoing supervision from the VEP. At the end of the 38 hours, the RA (i.e., lead RA trainer) was deemed competent by the VEP.

In the second phase, which took place the following fall, 4 new RAs entered TTT training for the current study. Phase 2 also served as booster training for the lead RA trainer. All new RAs were former PLs with 1-2 years of PL experience and who had been observed to be highly skilled when they were trained as PLs. They first attended a 1-hour orientation meeting during which the VEP and lead RA trainer provided pointers regarding effective supervision. Topics included the need to a) be very specific with regards to observed PL and participant behaviors so that specific PL behaviors could be reinforced and/or corrected, and also so that specific moments in the group could be problem solved; b) keep comprehensive and organized notes and strategies for providing specific feedback; c) address general group leadership skills and non-verbal communication strategies; d) reinforce every PL before providing constructive criticism; e) have a system for which RA trainer was in charge of managing timing of trainings, as well as a back-up plan should she lose track of time; and f) make sure that challenging sections of the intervention were fully understood by all PLs to the highest degree possible and that a list of key topics were covered during training (e.g., making sure that construction of perfect woman list was completed correctly, getting answers from all participants when instructions stated "go around the group," making sure that PLs understood how to model appropriate statements for various activities). 
After this session, the 4 new RA trainers participated in approximately 10 hours of cotraining with the VEP and the lead RA trainer (i.e., co-leading one training group of the PLs assigned to VEP+UT for the current study). Based on their performance during co-training with the VEP (VEP+UT), the strongest RA trainers were identified. The VEP and lead RA trainer from phase one then developed the RA training teams for the UTA condition, with a minimum of three RA trainers per team, for that first year of the current study. Every training team for the UTA trainings included the lead RA trainer for the remainder of the first year plus at least one RA who was deemed a top trainer. All RAs, however, were allowed to participate in training in both conditions. RAs also received additional supervision after trainings that were VEP+UT.

During phase three, which began in the second year of the study, two RAs who were already trained-to-train and were viewed as highly competent by the VEP based both on observations from the VEP+UT trainings and on observations from the previous year's lead RA during phase two, continued working on the study and served as the lead RA trainers. They received 10 hours of refresher training in the fall semester by co-training with the VEP in the VEP+UT condition, along with new RAs who were trained in the same manner as the four RAs as described during phase two. The fourth phase represented the maintenance of TTT trainings; throughout the remainder of the study, new RA trainers were blended in with experienced RA trainers in the same fashion and all RA trainers continued to serve in the $\mathrm{VEP}+\mathrm{UT}$ condition for ongoing supervision. UTA training groups were not audiotaped; RA trainers also were not supervised for UTA training sessions unless the RAs chose to bring questions to the VEP after the given training session had ended.

\section{The Study}

Sorority new members who participated in the Body Project program and consented to participate in the study completed questionnaires at baseline (pre-intervention), postintervention, and at 8-week, 8-month, and 14-month follow-up. Participants generated their own identification codes to maintain anonymity and reduce coercion. Undergraduate RAs administered follow-up measures at monthly sorority meetings or during individually scheduled time slots for a member did not attend meeting.

\section{Measures}

Thin-ideal internalization-We assessed thin-ideal internalization using the Ideal Body Stereotype Scale-Revised (IBSS-R; Stice \& Agras, 1998), which is a 10-item measure of beliefs about the ideal appearance characteristics of women. The participant ranks the degree to which she agrees or disagrees with statements regarding thinness on a 5-point Likert scale. Research indicates good internal consistency ( $a=.91 ; \alpha=.81$ in the present sample), test-retest reliability $(r=.80)$, and predictive validity for bulimic symptom onset (Stice et al., 2008).

Negative affect-We utilized the 20 items of the Sadness, Guilt, and Fear/Anxiety subscales of the Positive and Negative Affect Schedule (PANAS; Watson \& Clark, 1992) to assess negative affect. Items have a response format ranging from $1=$ very slightly or not at all to $5=$ extremely and participants report how much they have felt various negative 
emotions. The PANAS has good internal consistency ( $\alpha=.95 ; a=.90$ in the present sample) and test-retest reliability $(r=.78)$, as well as predictive validity for bulimic symptom onset (Stice, Trost, \& Chase, 2003).

Body satisfaction-We assessed body satisfaction with the Satisfaction with Body Parts Scale (SBPS; Berscheid, Walster, \& Bohrnstedt, 1973). The SBPS is a 9-item measure of body satisfaction on which participants rate their level of satisfaction with body parts on a scale ranging from $1=$ extremely satisfied to $6=$ extremely dissatisfied . Individual item scores are averaged for a total score. This scale has shown good internal consistency ( $a=$. 94; $a=.92$ in the present sample), test-retest reliability $(r=.90)$, and predictive validity for bulimic symptom onset (Stice et al., 2004).

Eating disorder symptoms-Eating disorder symptoms were assessed using the Eating Disorder Examination Questionnaire (EDE-Q; Fairburn \& Beglin, 1994), which is the selfreport version of the Eating Disorder Examination (EDE; Fairburn \& Cooper, 1993). The EDE-Q measures eating behaviors and attitudes over the past 28 days. We utilized the EDEQ global score in this study to assess overall eating disorder symptoms. Research supports the internal consistency $(\alpha=.92 ; a=.79$ in the present sample) and test-retest reliability ( $\mathrm{r}$ $=.90)$ (Stice, Shaw, Burton, \& Wade, 2006).

Self-objectification: self-surveillance, body shame, and body control-We used the 14-item Objectified Body Consciousness Scale (OBCS; McKinley \& Hyde, 1996), which is composed of three subscales: self-surveillance (4 items), body shame (5 items), and body control beliefs ( 5 items). Self-surveillance is a purported indicator of selfobjectification and includes items such as, "I often compare how I look with how other people look." The body shame subscale assesses the degree to which individuals experience shame when evaluating their own body, and includes items such as, "I would be ashamed for people to know what I really weigh.” The body control subscale measures the degree to which individuals believe that they are in control of their body appearance, including items such as, "I could look as good as I wanted to if I worked at it." Participants respond on a Likert scale of 1-7, where $1=$ strongly agree and 7= strongly disagree. We handled reversescored items such that higher scores represented more favorable views, and lower scores represented more problematic views. This OBCS has good internal consistency for the subscales $(\mathrm{a}=.66-.89)$. In this sample, internal consistency was $a=.85$ for the selfsurveillance, $a=.83$ for the body shame, and $a=.65$ for the body control.

\section{Data Analysis}

A series of latent growth mixture models (LGMMs) were used to examine heterogeneity in trajectory of change for each of the outcome variables (Aim 2) as well as the effect of trainer on outcomes (Aim 1). This method identifies a discrete number of trajectories (i.e., latent classes) in the repeated measures and assumes independent errors (McCardle \& Nesselroade, 2003) with the model estimated using a robust full information maximum likelihood estimator that treats data missing at random (MAR). 
For each outcome, we used the following model-building steps: a) unconditional no-change (intercept only) model; b) unconditional linear model (intercept and slope); c) unconditional quadratic model (intercept, slope, quadratic); and d) unconditional nonlinear spline (intercept, slope with freely estimated loading factors for follow-up time points). To determine the best fitting unconditional LGMM, we used Akaike information criterion (AIC), entropy, and sample-size adjusted BIC (aBIC), as well as the Lo-Mendell-Rubin adjusted likelihood ratio test (adjusted LRT), and parametric bootstrapped likelihood ratio test (BLRT) for differences between models (Lo, Mendell, \& Rubin, 2001; Nylund, Asparouhov, \& Muthén, 2007). The determination for best fitting model was based on lower criterion scores and significant $p$-values for LMR, BLRT, and adjusted LRT. After unconditional models were estimated, we examined the effect of trainer on trajectory and growth parameters. For all covariate analyses, we centered time on the end of the intervention period so that covariate effects could be interpreted as effect of covariate on mean differences at end of treatment.

\section{Results}

\section{Peer-Leader Adherence}

As noted above, in order to assess PL adherence and to evaluate potential differences in adherence across training groups, $60 \%$ of audio recordings of Body Project sessions were reviewed either by masters-level BIA trainers or trained undergraduate RAs. All raters were blind to PL training condition. To establish interrater reliability, we benchmarked the raters to a gold standard master trainer, the first author. Due to documented problems with the Cohen's kappa statistic (e.g., Gwet 2002), we assessed reliability using the Gwet's AC1 statistic (Gwet, 2002). Interrater reliability with the gold standard rater was very high (AC1 ranged from .97-1.00). All sessions rated evidenced acceptable adherence to the intervention protocol, with protocol adherence ranging from $88.7 \%$ to $100 \%$ of items rated as "mostly" or "fully" completed, and ranging from $80.7 \%$ to $100 \%$ rated as "fully completed." No differences in PL adherence to the protocol were noted between training conditions (VEP+UT: $M=96.26, S D=3.70$; UTA: $M=98.05, S D=2.17), t(19)=-1.41, p$ $=.175$.

\section{Model Fitting}

We found evidence for superiority of nonlinear splines for all outcomes. These models indicated initial change pre-post intervention followed by decelerating rates of change over the follow-up period. In all cases the random effects for both intercept and slope were significant, suggesting significant inter-individual variability in baseline symptom level and rates of symptom change over the course of the study. We the tested 1-4 class LGMMs (Table 1) to determine if there were unobserved trajectories in symptom change. It is important to note that these analyses address both Aim 1 and Aim 2 simultaneously.

Thin-ideal internalization-A two class model provided the best fit to the data (Aim 2). As shown in Figure 2, the trajectories of change reflect differences in the response to the intervention and the degree of improvement post-intervention. Class 1 included $24.8 \%$ of the sample and had a robust response to treatment, but lost more of these improvements over 
follow-up. In contrast, Class 2 (75.2\%) had a less robust response to the Body Project, although gains remained stable over follow-up. The covariate analyses (Aim 1) revealed that trainer was not a significant predictor of change within each individual class (Class $1, \beta=$ $-0.012, \mathrm{SE}=0.010, p=.21$; Class $2, \beta=-0.001, \mathrm{SE}=0.002, p=.93$ ), nor a significant predictor of class membership $(\beta=0.114, \mathrm{SE}=0.618, p=.85)$. The effect of trainer on thinideal internalization at the end of follow-up also was nonsignificant in Class $1(\beta=-0.023$, $\mathrm{SE}=0.755, p=.72)$ and Class $2(\beta=0.004, \mathrm{SE}=0.235 p=.89)$. Thus, our hypothesis regarding a trainer differences was not supported.

Negative affect-A three class model provided the best fit to the PANAS data (Aim 2). As shown in Figure 3, there was significant variability in affective changes within the sample. Class $1(74.1 \%)$ reported low levels of negative affect that remained low throughout follow-up. In contrast, Classes 2 and 3 had variable responses to the intervention and followup. Class $2(15.1 \%)$ experienced an initial decrease in negative affect in response to the intervention, but then worsened over the course of follow-up. Class $3(10.8 \%)$ had an opposite response pattern; these participants experienced an increase in negative affect following the Body Project that ultimately led to a stable improvement in negative affect. Covariate analyses (Aim 1) indicated that trainer type did influence trajectory of change, but did not moderate the effect of the intervention within the trajectory subgroups. Specifically, $\mathrm{VEP}+\mathrm{UT}$ trainer was a significant predictor of being in Class 2 compared to Class 1 ( $\beta=$ 3.575, $\mathrm{SE}=0.525, p<.001)$ and Class 1 over Class $3(\beta=-7.998, \mathrm{SE}=0.585, p<.001)$. Within each class, however, trainer type did not significantly predict change in negative affect over time (Class 1, $\beta=0.211, \mathrm{SE}=0.725, p=.411$; Class 2, $\beta=-0.241, \mathrm{SE}=0.425, p$ $=.289$; Class $3, \beta=0.012, \mathrm{SE}=.188, p=.344)$. Given that Class 3 showed the greatest overall improvement in negative affect, and given that trainer did not moderate intervention response within each trajectory, results again did not support our hypothesis that VEP+UT training would yield superior results.

Body satisfaction-The one class LGMM provided the best fit to the data suggesting that random variation in baseline severity or symptom improvement was not a function of unobserved subgroups (Figure 4). The one class showed an initial increase in body satisfaction that was largely maintained at follow-up. Trainer was not a significant predictor of slope $(\beta=0.211, \mathrm{SE}=0.421, p=.399)$. Thus, results did not support our hypotheses regarding trainer.

Eating disorder symptoms-A three class model provided the best fit to the data. As Figure 5 shows, there were two different improvement classes, and a smaller group that experienced relatively little benefit to the intervention. Class 1 (12.5\%) reported the highest level of eating disorder symptom severity and a robust response to the intervention that continued to improve over follow-up. Class 2 (22.3\%) reported intermediate symptom severity, but similarly robust response to the intervention that remained stable over followup. In contrast, Class 3 (65.2\% of the sample) reported low symptom severity and relatively little change pre- to post-intervention and over follow-up, possibly indicating floor effects. Trainer was not a significant predictor of trajectory class (Class 1 vs $2, \beta=0.021, \mathrm{SE}=$ $0.116, p=.298$; Class 1 vs $3, \beta=-0.041, \mathrm{SE}=0.216, p=.558$; Class 2 vs $3, \beta=0.089, \mathrm{SE}=$ 
$0.209, p=.621)$. Trainer was, however, a significant predictor of trajectory of change within each class. Within Class 1, being trained by VEP+UT was associated with an accelerated change over treatment and follow-up $(\beta=-1.641, \mathrm{SE}=0.264, p<.001)$. The opposite relationship was observed for Class 2 , where being trained by VEP+UT was associated with a decelerated rate of change $(\beta=0.787, \mathrm{SE}=0.192, p<.001)$. Trainer had no significant effect on rate of change in Class $3(\beta=0.039, \mathrm{SE}=0.067, p=.560)$. In summary, although trainer was associated with trajectory of improvement in two of the three classes, results did not consistently support the superiority of the VEP+UT training model.

Self-surveillance-The one class model provided the best fit to the data for selfsurveillance. Note that secondary to the way the measure was scored, increased scores indicate decreased surveillance. As depicted in Figure 6, there was improvement in selfsurveillance that stabilized after 2-month follow-up. Trainer was not a significant predictor of rate of change $(\beta=-0.007, \mathrm{SE}=0.008, p=.401)$. Thus, results did not support our trainer hypothesis.

Body shame-For body shame, there was evidence that a two class model provided the best fit (Figure 7). As with self-surveillance, increased scores indicate a decrease in shame. Class $1(10.8 \%)$ had greater shame and reported a temporary worsening in shame postintervention that returned to baseline levels in follow-up. In contrast, Class 2 participants (89.2\%) reported an initial improvement in shame that returned to baseline levels during follow-up. Trainer was not a significant predictor class $(\beta=0.114, \mathrm{SE}=0.189, p=.271)$ and trainer was not associated with variability in symptom change within class (Class $1, \beta=$ $0.002, \mathrm{SE}=0.145, p=.701$; Class $2, \beta=0.014, \mathrm{SE}=0.203, p=.596)$. Thus, our trainer hypothesis was not supported.

Body control-The two class solution also provided the best fit for body control (Figure 8). As with self-surveillance and body shame, increased scores represented improvement in body control. Class $1(87.6 \%)$ reported an initial post-intervention improvement in perceived body control that remained stable over follow-up. In contrast, Class 2 (12.4\%) reported stable body control in response to the intervention and throughout follow-up. Trainer was not a significant predictor of class membership $(\beta=-0.033$, $\mathrm{SE}=0.094, p=.405)$. Trainer was a significant predictor of rate of change in Class $1(\beta=-0.010, \mathrm{SE}=0.004, p<.05)$, however, with those trained by VEP+UT experiencing less improvement in body control over time. The same pattern was not true for Class $2(\beta=0.022, \mathrm{SE}=0.019, p=.148)$. In summary, the results again did not support our hypothesis.

\section{Discussion}

The present study had two primary aims. The first investigated the viability of using the TTT model to task-shift training of undergraduate PLs for the Body Project from a VEP to other undergraduate students. The second aim investigated whether or not subpopulations within the overall sample evidenced different trajectories of response to the Body Project.

Regarding the first aim, we found almost no evidence to support our hypothesis that having a VEP included in the training process yielded superior participant outcomes compared to 
training by UTA. Indeed, only one subgroup of participants for one measure evidenced better outcome with VEP+UT training. More specifically, for eating disorder symptoms as measured by the EDE-Q, participants in Class 1, who represented $12.5 \%$ of the sample and reported the highest level of eating disorder symptoms, showed greater improvement if their PLs had been trained by a VEP+UT versus UTA at 14-month follow-up. The opposite was true for Class 2, however, which included approximately $22 \%$ of the sample and reported intermediate ED symptoms. Moreover, we found no indications of VEP superiority for any other variables. These results suggest that with appropriate training, not only can undergraduates successfully run Body Project groups, they also can be trained-to-train other undergraduates.

Furthermore, these results provide some controlled support for the training approach used in BIA during our real-world national dissemination effort. Although the methods used in this study and BIA were not identical, in both cases undergraduate students were provided with in-depth, experiential training by a VEP/MEP. This study therefore provides initial support via a controlled trial for the use of a blended task-shifting/TTT approach in dissemination of the Body Project. This is important because the blended task-shifting/TTT approach was necessary to reach the dissemination goals that we set when we designed BIA as our dissemination mechanism. Task-shifting alone clearly was going to be insufficient.

Results from this study also provide additional support for continued efforts to disseminate the Body Project. Fairburn and Wilson (2013) identified three factors that influence the degree to which psychological treatments may be easier or harder to disseminate and implement. Although their review focused on treatment, their comments apply equally to prevention. The first, intervention delivery characteristics or mode of treatment delivery, includes factors such as the medium through which the intervention is delivered (e.g., faceto-face, individual versus group, web-based) as well as the level of provider expertise required (i.e., capacity for employing task-shifting). The second involves the ease with which interventions can be learned by providers and trainers (i.e., the potential for train-thetrainer methodology). The final factor pertains to the range of patients/individuals for which the intervention is appropriate.

With regards to factor one, certain delivery characteristics are generally thought to facilitate dissemination and implementation. For instance, programs that can be delivered via less labor-intensive mediums are thought to be more facilitative of dissemination and implementation. In this area the Body Project receives a mixed score. On the negative side, it is a face-to-face intervention that works best when a trained provider implements it. This means it has greater labor requirements than some web-based interventions and that participants have less flexibility in when they attend. It should be noted that some web-based interventions have moderated discussion groups, which increases labor demands. In addition, although it is generally assumed that web-based prevention programs will have greater reach, this has not yet been proven in the area of eating disorders prevention (Atkinson \& Wade, 2013). On the positive side, however, the Body Project is a group intervention, which makes it less labor intensive than a face-to-face individual intervention. Also positive, and falling within the domain of delivery characteristics, is the fact that 
research clearly shows that delivery of the Body Project can be task-shifted to lay persons (Becker et al., 2006, 2008; 2010).

In terms of factor two, ease of learning, the present study provides substantial support for Body Project ease of learning at the trainer level. As noted above, ease of learning was relatively well supported at the provider level, and being able to task-shift delivery of the Body Project away from VEPs/MEPs to undergraduate PLs markedly increased the scalability of the Body Project. Nonetheless, VEP/MEP trainer time and cost remained limiting factors when we sought to expand on a national scale, and no controlled study addressed the degree to which a TTT model in which training was task-shifted to lay persons was viable for the Body Project. Our failure to find consistent advantages with a $\mathrm{PhD}$ level trainer versus undergraduate students clearly shows that it is possible to markedly increase the number of people who are capable of training lay providers of the Body Project, and that trainers do not need to have advanced degrees.

Finding evidence indicating that the trainer role also can be task-shifted further supports the increased scalability of the Body Project from time and cost perspectives. Importantly, undergraduate students have shown a remarkable willingness to volunteer time to serve as both PLs and trainers - thus their cost is quite low. At BIA, most undergraduate students who were trained-to-train PLs at their home institution received leadership positions within their sorority chapter and/or service credit from their chapter, but they were not paid. For this research project, RAs who served as trainers received course credit for their participation. Yet most worked many hours above and beyond what was required out of dedication to the aims of the Body Project and a belief that the program changes lives. All RAs began their Body Project journey as participants in earlier studies progressing from participant, to peer-leader to RA/trainer. Thus, the loyalty engendered by the Body Project also appears to contribute to its scalability. Lastly, results signifying high protocol adherence further supports a high ease of learning for the Body Project at both the provider and trainer level.

With regards to factor three, clinical range, the current study provides additional support for the Body Project through our Aim 2 analyses (see below). As noted by Fairburn and Wilson (2013), as a field we need programs that are useful for the broadest range of individuals.

Clinical range also should involve documenting that programs do not cause significant harm to subsets of individuals. This is particularly important for an intervention like the Body Project which is often, as in the present study, delivered on a semi-mandatory basis. Previous research also provides some support for the clinical range of the Body Project. For instance, research already indicated that the Body Project is beneficial for both lower- and higher-risk individuals, with body dissatisfaction levels being used to determine risk status (Becker et al., 2008).

Regarding Aim 2, we sought to determine if there were different trajectories of response to the Body Project as it is increasingly being recognized that mean response in a sample may mask important heterogeneity. For instance, in an analysis of seven antidepressant trials, Gueorguieva et al. (2011) found that while medication responders showed marked improvement relative to placebo, medication non-responders showed a significant 
worsening trajectory relative to placebo. Thus, investigating trajectories not only can provide important scientific information to better predict outcomes, but also can raise red flags regarding the potential for some individuals to respond poorly to an intervention. This type of information can be very important if the goal is to broadly disseminate an intervention in a public health-like manner using lay providers and even lay trainers. Under such a scenario, one ideally wants interventions that are not only beneficial for responders, but are largely benign for non-responders or for those who are at such low risk they are unable to demonstrate response secondary to floor effects.

Trajectory analyses provided support for broad dissemination of the Body Project. Out of 14 classes identified for all variables collectively, only one class for one variable (Class 2 for negative affect; $15 \%$ of sample) showed any negative response. Further, even at 14 months the degree of worsening relative to baseline was quite small (i.e., approximately $13 \%$ relative to baseline). We should note that because we lacked a no-intervention assessment group, it is not possible to tell if this class of participants would have shown worsening of negative affect regardless of the intervention. It may be that the Body Project's effect on negative affect (which is not a core target of this intervention) is insufficient to stop from worsening a group who would naturally worsen over the course of the study without intervention. Also, it is important to note that the present sample offered a good test for these types of analyses because the program was delivered on a semi-mandatory basis to all members of a university sub-community. Thus, both lower- and higher-risk members participated.

In addition, for the three most relevant variables, which are the key theoretical targets of the Body Project (i.e., thin-ideal internalization, body dissatisfaction, and eating disorder symptoms), virtually all trajectories that emerged showed improvement. Although Class 3 for eating disorders symptoms showed minimal improvement, participants in this Class reported very low levels of eating disorder symptoms at baseline; thus there was little room for improvement (i.e., floor effect). With regards to self-objectification (i.e., selfsurveillance) and related constructs (body shame and body control) participants either improved or showed no long-term response across all classes. Therefore, even when investigating various trajectories of change across classes of participants, results indicated that experiences were largely beneficial.

It is important to note that our results providing support for a blended task-shifting/TTT strategy for disseminating the Body Project may be limited to preventive interventions, and less applicable to mental health treatments. Specifically, prevention programs often are constructed in such a way as to facilitate delivery by non-expert, community, or lay providers. By definition, they also target populations with lower levels of mental health concerns. Therefore, preventive interventions may be more amenable to a task-shifting/TTT blended model than are psychological treatments. It very well may be the case that a natural floor exists in the task-shifting of training for psychological treatments and that the maximum possible level of shift is from VEP to MEP, thus generating a limit in this model in the context of treatment. Given the call for a focus on scalable prevention efforts in mental health (Kazdin \& Blase, 2011), however, evidence supporting methods for scaling up 
preventive interventions is needed independent of demands to increase access to mental health care.

\section{Limitations and Future Directions}

Whereas this study affords promising results regarding the blended task-shifting/TTT dissemination model, a notable limitation is the lack of a no-intervention control condition. Although we did randomly assign PLs to training condition and participants to PL training condition, an assessment-only control group would provide information regarding natural change over time in this environment. It is important to note, however, that the primary aim of this study was to investigate a dissemination and implementation question, not to contribute to the already substantial efficacy and effectiveness literature for the Body Project.

Additionally, in spite of strong efforts to randomize PLs to training condition, time and scheduling constraints dictated randomization to some extent. Although these instances were rare, such instances prevented us from employing a pure randomization of PLs to training conditions. There did not appear to be any PL characteristics that systematically interfered with randomization (e.g., responsibility, commitment, dedication to the program); rather scheduling conflicts appeared to be more related to the limited number of trainings offered (four trainings per year).

A further limitation is the fact that we only assessed adherence and not competence. Adherence was very high across both conditions (VEP+UT $=96.26 \%$, UTA $=98.05 \%)$, but reviewers noted there seemed to be a bit more variability in peer-leader skill in extracting comments from participants. This was not systematically examined. Given the lack of consistent differences in participant outcomes between the two conditions, however, it may be that observed variation played little role in outcomes or was evenly distributed across conditions. Nonetheless, future research needs to examine both adherence and competence not only for intervention leaders but also trainers. Lack of adherence and/or competence at either level will obviously threaten the utility (e.g., efficiency and cost savings) of the blended task-shifting/TTT model.

This study also is limited by the exclusive use of self-report measures to assess intervention outcomes in participants. A further potential limitation is our strategy of allowing PLs to self-screen based on the presence of an active eating disorder or significant body image concerns. On the one hand this could be viewed as a limitation in that we cannot guarantee that PLs did in fact self-screen. On the other hand, this is a tightknit community and only three times over the past decade have other PLs raised concerns when they felt a potential PL did not self-screen. As such, we think the strategy has largely worked. Further, one could argue that this increases generalizability. Notably, we adopted the self-screening approach secondary to our use of community participatory research methods. Community leaders felt it was important to allow members to make the decision.

Finally, although we view the use of community participatory research methods as a strength of our research program, we also recognize that it potentially limits generalizability. More specifically, this study relied on a longstanding partnership with a community that was 
developed using a community participatory research framework (see Becker et al., 2009 for additional detail). For instance, everyone involved in running/designing study, with the exception of the last author, is a member of that community. As noted above, undergraduate RA trainers started as participants in earlier studies, then graduated to serving as PLs and ultimately assumed further leadership by designing and running studies. RAs also frequently held other leadership positions in their community (e.g., co-chair of the overarching judicial/ decision making body for all sororities and fraternities, president of a specific sorority, philanthropy chair, etc.). As such, they were not only members of their community; they were leaders in more than one respect. Thus, it is possible that their leadership roles granted them a level of authority that facilitated the success of the blended task-shifting/TTT model in a way that would not have otherwise occurred. In other words, future research will be needed to determine if the blended task-shifting/TTT model works for prevention in a less hierarchical community.

Future studies assessing cross-campus and cross-university implementation of the taskshifting/TTT methodology and investigating response classes to Body Project participation on this broader scale also would be beneficial in further examining the scalability of the Body Project using this dissemination strategy. In particular, research is needed to determine if our differential findings for participants with the highest levels of eating disorder symptoms at baseline replicate. If future research supports the finding that participants with the highest level of baseline eating disorder symptoms benefit more from receiving the program by PLs who are VEP trained, then this would suggest that pre-screening participants might be useful. We are reluctant to conclude this at this time, however, given that this is the first study of its kind for the Body Project and given the finding that participants with the next highest level of eating disorder symptoms benefitted more in the UTA condition. Future research also is needed investigate other strategies for scaling up the Body Project, as well as other implementation targets such as participant recruitment and factors related to adoption. Lastly, from a dissemination and implementation research perspective, future research needs to identify to what degree a blended task-shifting/TTT model works for other EBIs.

\section{Acknowledgments}

The authors would like to thank Chantale Wilson, Jessica Turner, Rebecca Ribbing, Rachel Hugman, Miquela Garcia, Leigh Carver, and Ana Martinez for their contributions to this study.

The writing of this manuscript was supported by the National Institute of Mental Health grant R01 MH094448-01A1.

\section{References}

Atkinson MJ, Wade TD. Enhancing dissemination in selective eating disorders prevention: An investigation of voluntary participation among female university students. Behaviour Research and Therapy. 2013; 51(12):806-816. [PubMed: 24140874]

Becker CB, Bull S, Schaumberg K, Cauble A, Franco A. Effectiveness of peer-led eating disorders prevention: A replication trial. Journal of Consulting and Clinical Psychology. 2008a; 76(2):347354. [PubMed: 18377130] 
Becker CB, Bull S, Smith LM, Ciao AC. Effects of being a peer-leader in an eating disorder prevention program: Can we further reduce eating disorder risk factors? Eating Disorders. 2008b; 16(5):444-459. [PubMed: 18821367]

Becker, CB.; Mackenzie, K.; Stewart, T. Cognitive and behavioral approaches to the prevention of eating disorders. In: Levine, M.; Smolak, L., editors. Wiley-Blackwell handbook of eating disorders. Hoboken: John Wiley \& Sons, Ltd; in press

Becker CB, Smith LM, Ciao AC. Reducing eating disorder risk factors in sorority members: A randomized trial. Behavior Therapy. 2005; 36:245-253.

Becker CB, Smith LM, Ciao AC. Peer-facilitated eating disorder prevention: A randomized effectiveness trial of cognitive dissonance and media advocacy. Journal of Counseling Psychology. 2006; 53(4):550-555.

Becker CB, Stice E, Shaw H, Woda S. Use of empirically supported interventions for psychopathology: Can the participatory approach move us beyond the research-to-practice gap? Behaviour Research and Therapy. 2009; 47(4):265-274. [PubMed: 19281965]

Becker CB, Wilson C, Williams A, Kelly M, McDaniel L, Elmquist J. Peer-facilitated cognitive dissonance versus healthy weight eating disorders prevention: A randomized comparison. Body Image. 2010; 7(4):280-288. [PubMed: 20638351]

Berscheid E, Walster E, Bohrnstedt G. The happy American body: A survey report. Psychology Today. 1973; 7(6):119-131.

Centers for Disease Control and Prevention (CDC). Achievements in public health, 1900-1999: Changes in the public health system. MMWR Morbidity and mortality weekly report. 1999; 48(50):1141-1147. Retrieved June 12, 2014, from http://www.cdc.gov/mmwr/preview/ mmwrhtml/mm4850a1.htm.

Fairburn CG, Beglin S. Assessment of eating disorders: Interview or self-report questionnaire? International Journal of Eating Disorders. 1994; 36:376-388.

Fairburn, CG.; Cooper, Z. The Eating Disorder Examination. In: Fairburn, CG.; Wilson, GT., editors. Binge eating: Nature, assessment, and treatment. 12. New York: Guilford Press; 1993.

Fairburn CG, Patel V. The global dissemination of psychological treatments: A road map for research and practice. The American Journal of Psychiatry. 2014; 171(5):495-498. [PubMed: 24788281]

Fairburn CG, Wilson GT. The dissemination and implementation of psychological treatments: Problems and solutions. International Journal of Eating Disorders. 2013; 46(5):516-521. [PubMed: 23658103]

Festinger, L. A theory of cognitive dissonance. Stanford, CA: Stanford University Press; 1957.

Gueorguieva R, Mallinckrodt C, Krystal JH. Trajectories of depression severity in clinical trials of duloxetine: Insights into antidepressant and placebo responses. Archives of General Psychiatry. 2011; 68(12):1227-1237. [PubMed: 22147842]

Gwet K. Kappa statistic is not satisfactory for assessing the extent of agreement between raters. Statistical Methods for Inter-rater Reliability Assessment. 2002; 1:1-6.

Herschell AD, Kolko DJ, Baumann BL, Davis AC. The role of therapist training in the implementation of psychosocial treatments: A review and critique with recommendations. Clinical Psychology Review. 2010; 30(4):448-466. [PubMed: 20304542]

Israel, BA.; Eng, E.; Schulz, AJ.; Parker, EA. Introduction to methods in community-based participatory research for health. In: Israel, BA.; Eng, E.; Shulz, AJ.; Parker, EA., editors. Methods in community-based participatory research for health. San Francisco: Jossey-Bass; 2005. p. 3-26.

Jacobi, C.; Fittig, E. Psychosocial risk factors for eating disorders. In: Agras, WS., editor. Oxford handbook of eating disorders. New York: Oxford University Press; 2010. p. 123-135.

Jacobi C, Hayward C, de Zwaan M, Kraemer HC, Argas WS. Coming to terms with risk factors for eating disorders: Application of risk terminology and suggestions for general taxonomy. Psychological Bulletin. 2004; 130(1):19-65. [PubMed: 14717649]

Kazdin AE, Blase SL. Rebooting psychotherapy research and practice to reduce the burden of mental illness. Perspectives on Psychological Science. 2011; 6(1):21-37.

Lilienfeld SO, Ritschel LA, Lynn SJ, Brown AP, Cautin RL, Latzman RD. The research-practice gap: Bridging the schism between eating disorder researchers and practitioners. International Journal of Eating Disorders. 2013; 46(5):386-394. [PubMed: 23658076] 
Lo Y, Mendell NR, Rubin DB. Testing the number of components in a normal mixture. Biometrika. 2001; 88(3):767-778.

Matusek JA, Wendt SJ, Wiseman CV. Dissonance thin-ideal and didactic healthy behavior eating disorder prevention programs: Results from a controlled trial. International Journal of Eating Disorders. 2004; 26:376-388. [PubMed: 15558649]

McArdle JJ, Nesselroade JR. Growth curve analysis in contemporary research. Handbook of psychology. 2003:447-480.10.1002/0471264385.wei0218

McHugh RK, Barlow DH. The dissemination and implementation of evidence-based psychological treatments: A review of current efforts. American Psychologist. 2010; 65(2):73-84. [PubMed: 20141263]

McHugh, RK.; Barlow, DH. Training in evidence-based psychological interventions. In: McHugh, RK.; Barlow, DH., editors. Dissemination and implementation of evidence-based psychological interventions. New York, NY: Oxford University Press; 2012. p. 43-58.

McKinley NM, Hyde JS. The objectified body consciousness scale: Development and validation. Psychology of Women Quarterly. 1996; 20:181-215.

Nylund KL, Asparouhov T, Muthén BO. Deciding on the number of classes in latent class analysis and growth mixture modeling: A Monte Carlo simulation study. Structural Equation Modeling. 2007; 14(4):535-569.

Patel V, Chowdhary N, Rahman A, Verdeli H. Improving access to psychological treatments: Lessons from developing countries. Behaviour Research and Therapy. 2011; 49(9):523-528. [PubMed: 21788012]

Perez M, Becker CB, Ramirez A. Transportability of an empirically supported dissonance-based prevention program for eating disorders. Body Image. 2010; 7(3):179-186. [PubMed: 20335084]

Proctor EK. Leverage points for the implementation of evidence-based practice. Brief Treatment and Crisis Intervention. 2004; 4(3):227-242.

Proctor EK, Landsverk J, Aarons G, Chambers D, Glisson C, Mittman B. Implementation research in mental health services: An emerging science with conceptual, methodological, and training challenges. Administration and Policy in Mental Health and Mental Health Services Research. 2009; 36(1):24-34. [PubMed: 19104929]

Roehrig M, Thompson JK, Brannick M, van den Berg P. Dissonance-based eating disorder prevention program: A preliminary dismantling investigation. International Journal of Eating Disorders. 2006; 39(1):1-10. [PubMed: 16254869]

Stice E, Agras WS. Predicting onset and cessation of bulimic behaviors during adolescence: A longitudinal grouping analysis. Behavior Therapy. 1998; 29:257-276.

Stice E, Becker CB, Yokum S. Eating disorder prevention: Current evidence-base and future directions. International Journal of Eating Disorders. 2013; 46(5):478-485. [PubMed: 23658095]

Stice E, Chase A, Stormer S, Appel A. A randomized trial of a dissonance-based eating disorder prevention program. International Journal of Eating Disorders. 2001; 29:247-262. [PubMed: $11262503]$

Stice E, Marti CN, Spoor S, Presnell K, Shaw H. Dissonance and healthy weight eating disorder prevention programs: Long-term effects from a randomized efficacy trial. Journal of Consulting and Clinical Psychology. 2008a; 76(2):329-340. [PubMed: 18377128]

Stice E, Mazotti L, Weibel D, Agras W. Dissonance prevention program decreases thin-ideal internalization, body dissatisfaction, dieting, negative affect, and bulimic symptoms: A preliminary experiment. International Journal of Eating Disorders. 2000; 27:206-217. [PubMed: 10657894]

Stice, E.; Presnell, K. The body project: Promoting body acceptance and preventing eating disorders, facilitator guide. New York: Oxford University Press; 2007.

Stice E, Rohde P, Durant S, Shaw H, Wade E. Effectiveness of peer-led dissonance-based eating disorder prevention groups: Results from two randomized pilot trials. Behavior Research and Therapy. 2013; 51:197-206.

Stice E, Rohde P, Gau J, Shaw H. An effectiveness trial of a dissonance-based eating disorder prevention program for high-risk adolescent girls. Journal of Consulting and Clinical Psychology. 2009; 77:825-834. [PubMed: 19803563] 
Stice E, Rhode P, Gau J, Shaw H. Effect of a dissonance-based prevention program on risk for eating disorder onset in the context of eating disorder risk factors. Prevention Science. 2012; 13(2):129139. [PubMed: 21975593]

Stice, E.; Rohde, P.; Shaw, H. Facilitator guide. New York, NY: Oxford University Press; 2013. The body project: A dissonance-based eating disorder prevention intervention (Updated ed.).

Stice E, Rohde P, Shaw H, Gau J. An effectiveness trial of a selected dissonance-based eating disorder prevention program for female high school students: Long-term effects. Journal of Consulting and Clinical Psychology. 2011; 79:500-508. [PubMed: 21707136]

Stice E, Shaw H, Becker CB, Rohde P. Dissonance-based interventions for the prevention of eating disorders: Using persuasion principles to promote health. Prevention Science. 2008; 9:114-128. [PubMed: 18506621]

Stice E, Shaw H, Burton E, Wade E. Dissonance and healthy weight eating disorder prevention programs: A randomized efficacy trial. Journal of Consulting and Clinical Psychology. 2006; 74:263-275. [PubMed: 16649871]

Stice E, Trost A, Chase A. Healthy weight control and dissonance-based eating disorder prevention programs: Results from a controlled trial. International Journal of Eating Disorders. 2003; 33:10 21. [PubMed: 12474195]

Stice E, Ziemba C, Margolis J, Flick P. The dual pathway model differentiates bulimics, subclinical bulimics, and controls: Testing the continuity hypothesis. Behavior Therapy. 1996; 27(4):531-549.

Wade WA, Treat TA, Stuart GL. Transporting an empirically supported treatment for panic disorder to a service clinic setting: A benchmarking strategy. Journal of Consulting and Clinical Psychology. 1998; 66(2):231-239. [PubMed: 9583326]

Wilson GT, Zandberg LJ. Cognitive-behavioral guided self-help for eating disorders: Effectiveness and scalability. Clinical Psychology Review. 2012; 32(4):343-357. [PubMed: 22504491]

Zandberg LJ, Wilson GT. Train-the-trainer: Implementation of cognitive behavioural guided self-help for recurrent binge eating in a naturalistic setting. European Eating Disorders Review. 2012; 21(3): 230-237. [PubMed: 23109361] 


\section{Highlights}

- We examined a hybrid task-shifting/train-the-trainer strategy for enhancing scalability

- Undergraduate students were trained-to-train other students in delivery of the Body Project

- We assessed participant intervention outcomes and trajectories of change through 14-month follow-up

- Results supported use of task-shifting/train-the-trainer model for prevention

- Almost all trajectories indicated improvement or benign response to the intervention 


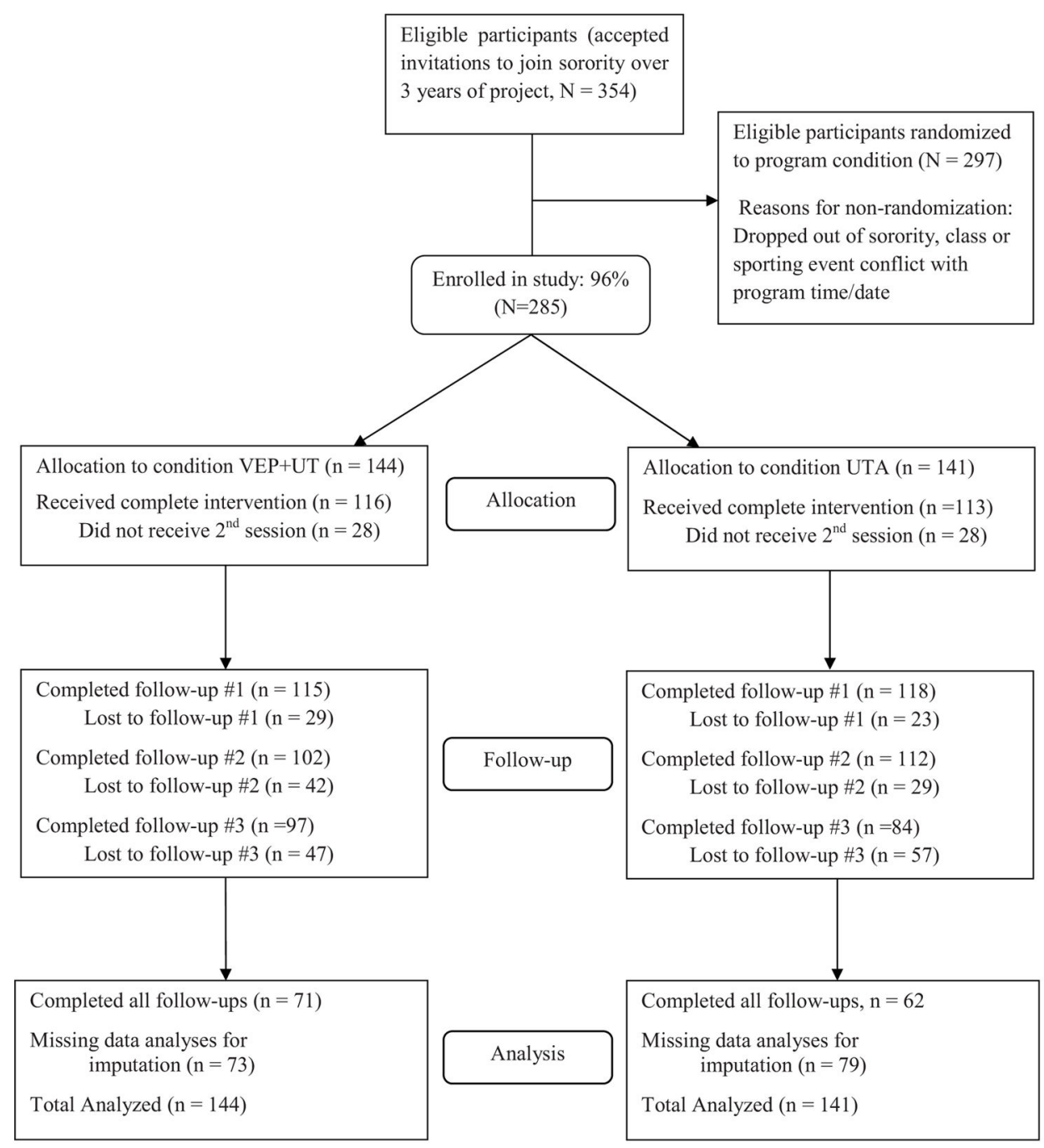

Figure 1.

Overview of Participant Flow

Behav Res Ther. Author manuscript; available in PMC 2015 December 01. 


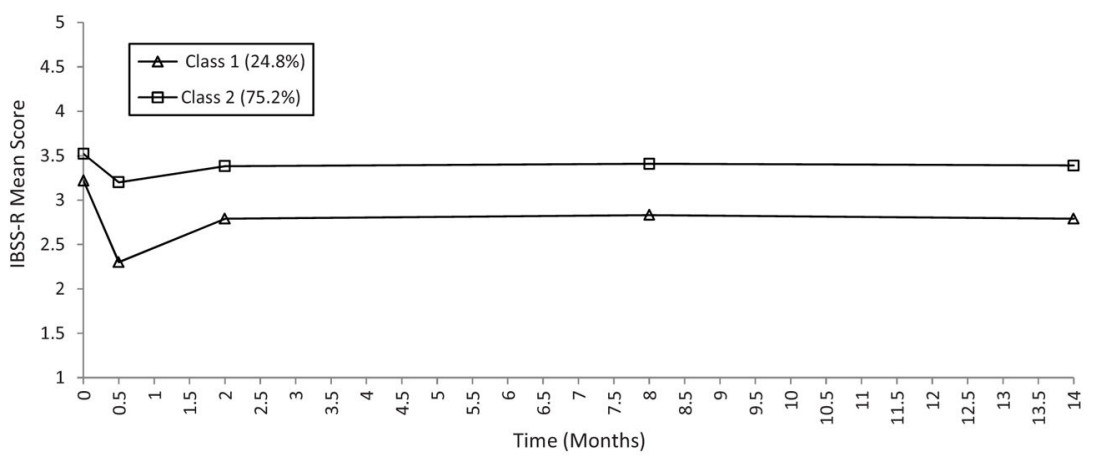

Figure 2.

Sample Means for Trajectory Classes for IBSS-R

Note: IBSS-R = Ideal Body Stereotype Scale - Revised 


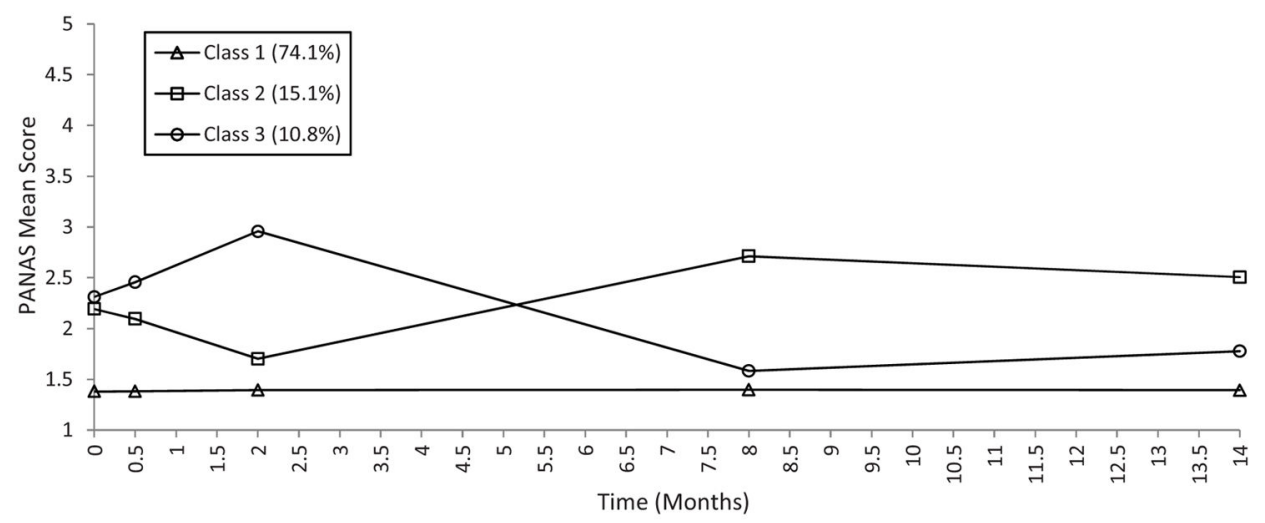

Figure 3.

Sample Means for Trajectory Classes for PANAS

Note: PANAS = Positive and Negative Affect Schedule, negative affect subscale 


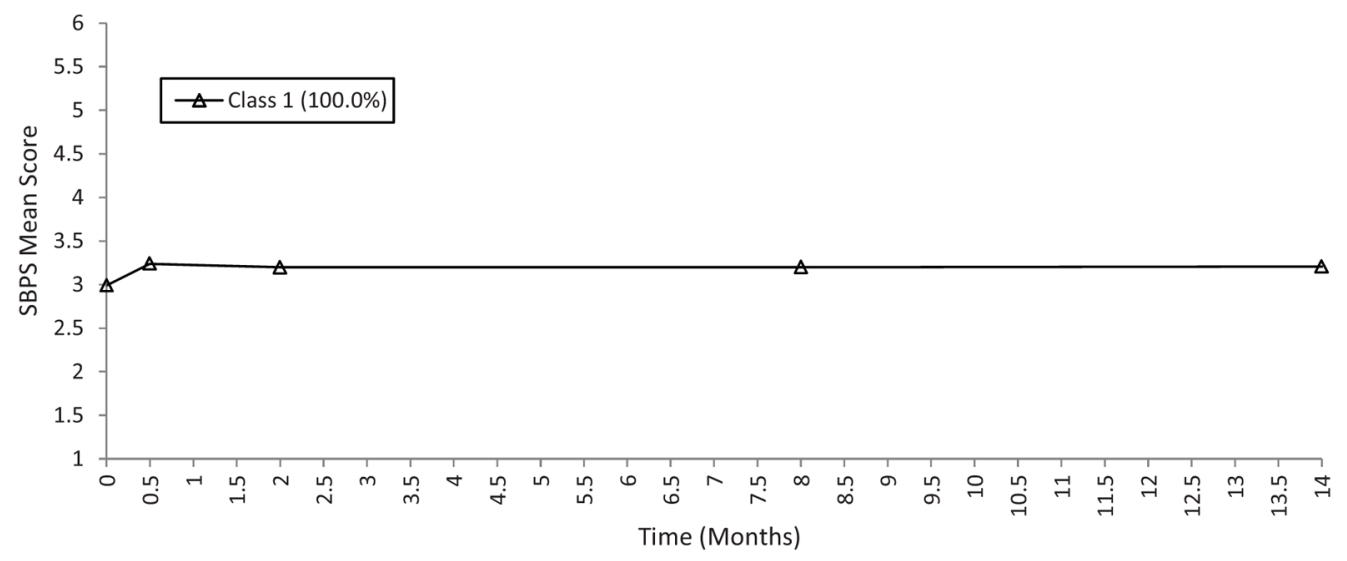

Figure 4.

Sample Means for Trajectory Classes for SBPS

Note $:$ SBPS $=$ Satisfaction with Body Parts Scale 


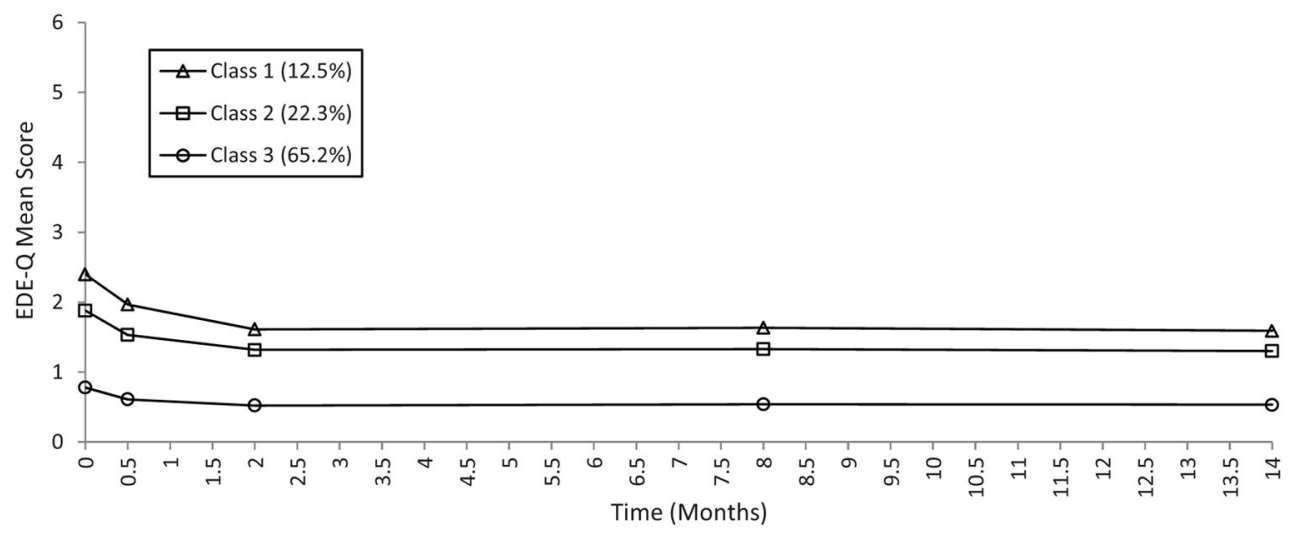

Figure 5.

Sample Means for Trajectory Classes for EDE-Q Global Score

Note: EDE-Q = Eating Disorder Examination - Questionnaire global score 


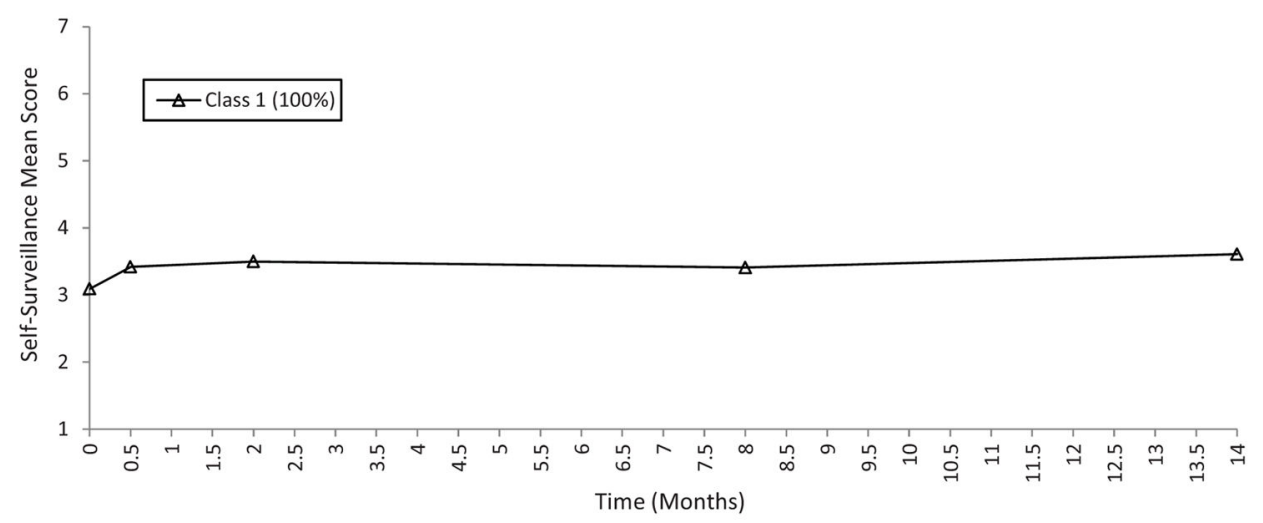

Figure 6.

Sample Means for Trajectory Classes for Self-Surveillance

Note: Self-Surveillance $=$ Objectified Body Consciousness Scale, self-surveillance subscale 


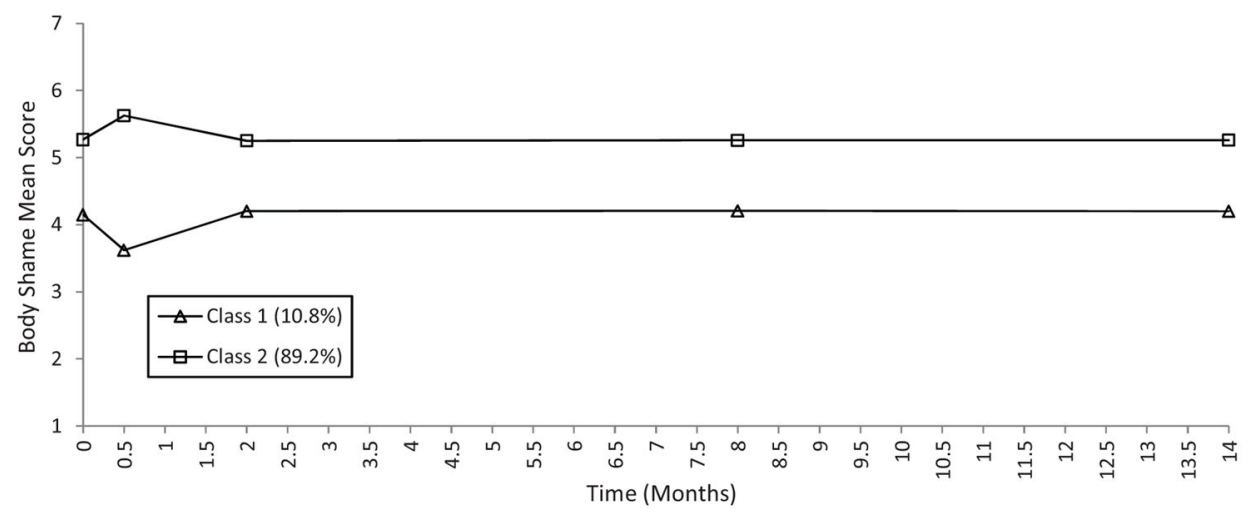

Figure 7.

Sample Means for Trajectory Classes for Body Shame

Note: Body Shame = Objectified Body Consciousness Scale, body shame subscale 


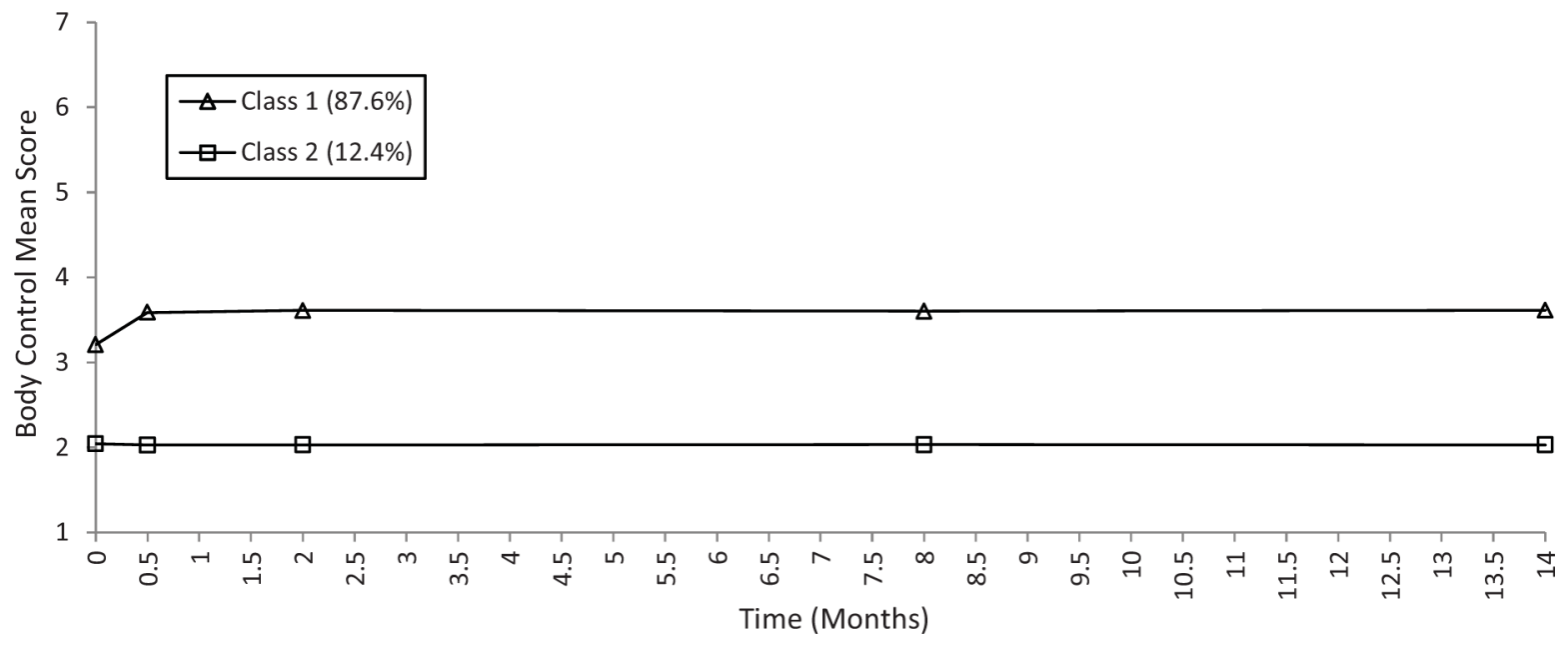

Figure 8.

Sample Means for Trajectory Classes for Body Control

Note: Body Control = Objectified Body Consciousness Scale, body control subscale 


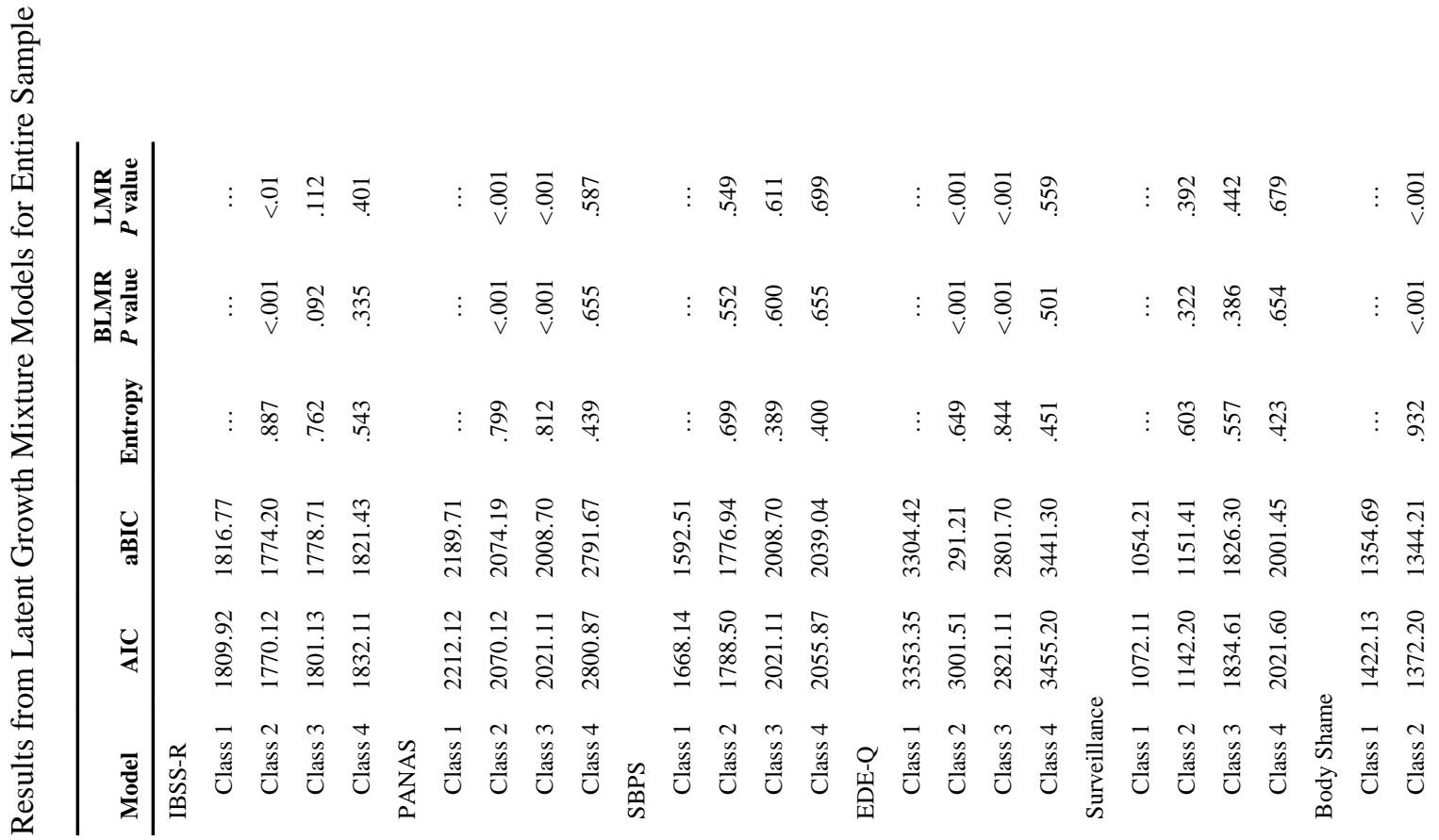




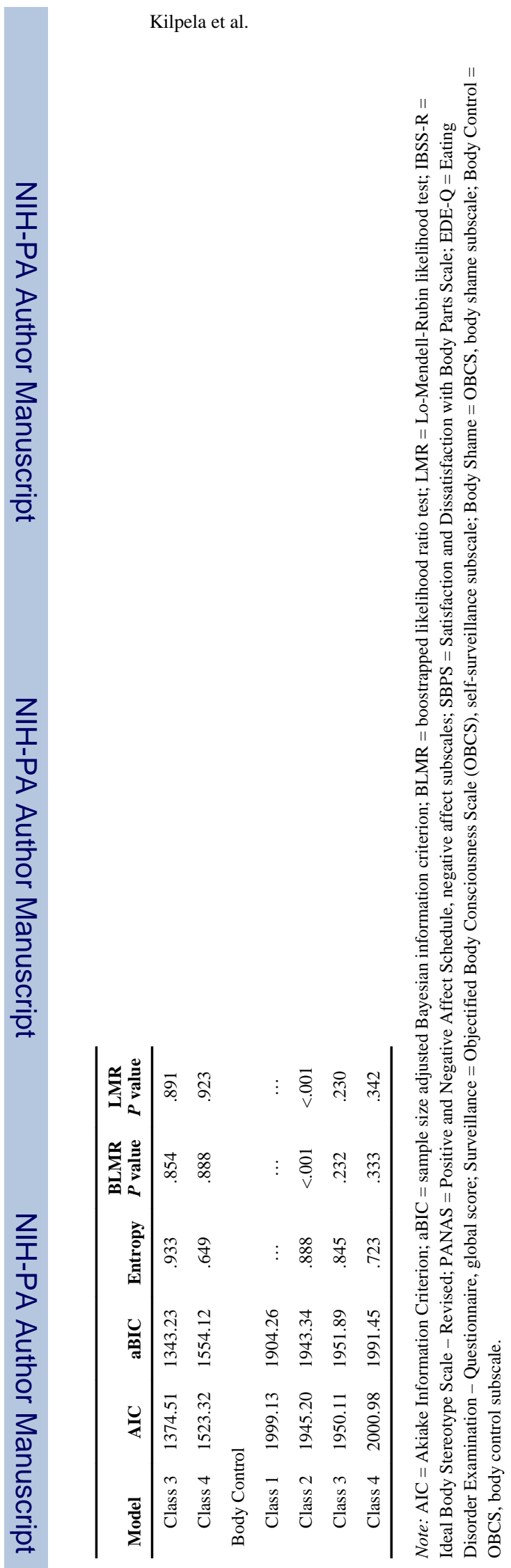

Behav Res Ther. Author manuscript; available in PMC 2015 December 01. 